\title{
The Design of A New Type of Apparatus For Large Turbo Generator Core Loss Test
}

\author{
Ming $\mathrm{LI}^{1, \mathrm{a}^{*}}$, Fuchun SUN ${ }^{1, \mathrm{~b}}$, Guangke XU ${ }^{1, \mathrm{c}}$, Weiwei ZHANG ${ }^{1, \mathrm{~d}}$, \\ Tao QIU ${ }^{2, e}$ \\ ${ }^{1}$ State Grid Shandong Electric Power Research Institute, Jinan, 250002, China \\ ${ }^{2}$ Shandong Zhongshiyitong Group Co., Ltd. Jinan, 250002, China \\ aliming88419@163.com, ${ }^{b} 353373462 @ q q . c o m,{ }^{c} x u g u a n g k e s d @ 163 . c o m,{ }^{d} 497238040 @ q q . c o m$, \\ e13668816013@163.com
}

Keywords: Core loss test, hours of work, test apparatus, group of test cables, switch cabinet Abstract. The core loss test is an common-used method to diagnose the core fault of large turbo generator. However, it takes a lot of time to connect cables before and disconnect cables after the power-on test using traditional operational approach. To make the core loss test more convenient to conduct, a new type of apparatus for large turbo generator core loss test is designed, which is introduced in detail in this paper and compared with traditional approach by analyzing hours of work to take. At last, the overall properties of the aparatus is summarized.

\section{Introduction}

As a preventive test of large turbo generator, the high flux core loss test is widely used to analyze the generator core state and find fault location in power plant when necessary. Recently, the Electromagnetic Core Imperfection Detector (ELCID) method is gradually used[1], however, due to the lack of state standard and the expensive equipment, it encounters some difficulties when introduced to the power plant engineers. As a result, in most cases, engineers choose to use high flux core loss test. As it takes too much hours of work to connect and disconnect the test cables, a new type of apparatus is designed to solve this problem, which would highly reduced the hours of work, thus level up the operation efficiency. The apparatus could be used for types of typical large turbo generators inland. Design of the apparatus mainly include: collect statistics of the core parameters of domestic typical large turbo generators and compute test datas concerned; determine the new connecting method of test cables and the length of each cable after segmentation.; design the switch cabinet for test use; combine the cable after segmentation and the switch cabinet.

\section{Analysis of the Design}

As a matter of fact, there is no fixed complete equipment for traditional generator core loss test. According to operation experience, technicians usually improvise a whole $6 \mathrm{kV}$ electric cable with length of several hundreds, which will be first draged and tagged to the $12.6 \mathrm{~m}$ high generator platform and then prepared for winding the generator core several turns. Heavy cables, extraordinary structure of the core, demanding only mannual operation, all lead to huge amount of hours of work, consuming three hours or more. Besides, afte the power-on test, it takes the same time to place cables back. As we all know, hours of work for connecting and disconnecting cables accounts for most time of the whole test, which makes the test exhausing and inconvenient. On the other hand, technicians stay too much time in the stator and core, bringing contamination of dirt or even damaging the winding bar for unskilled operation, which are all uncertainties not wished to see.

Take a 300MW turbo generator for example, using a 300m long test cable to wind the generator core 15turns, supposing that the unit mass of the cable be $1.5 \mathrm{~kg} / \mathrm{m}$ and the friction factor between the technician and the ground be 1.0, the winding work using traditional operation method is: 


$$
W=\int_{0}^{300} 1.0 \times 1.5 \times(300-x) \cdot 9.8 \cdot d x=661.5 \mathrm{~kJ} .
$$

Equivalent to lift the whole cable manually up to:

$$
h=\frac{661.5}{9.8 \times 300 \times 1.5} m=150 m
$$

The ultimate reason for taking so much hours to work lies in that the whole cable is tagged all the time, which is unnecessary. Assuming that we use a group of short cables for the test , a better result may be achieved. For example, the work to make during the operation while winding with 12 section of $25 \mathrm{~m}$ long cables is:

$$
W^{*}=12 \times \int_{0}^{25} 1.0 \times 1.5 \times(25-x) \cdot 9.8 \cdot d x=55.125 k J
$$

Work-saved coefficient is:

$$
k=W / W^{*}=661.5 \div 55.125=12
$$

It can be seen that using a group of short cables can largely reduce hours of work for winding the generator core. Thus, the design of the apparatus is extended out in this way.

\section{Constitution of the Apparatus}

The apparatus is mainly consist of a group of test cables and a switch cabinet.

Group of Test Cables. To satisfy the demands of different types of generators' core loss test and reduce the total length of the cables as possible as can, a goup of test cables which is comprised of short cables of different length and numbers. When conducting the core loss test, the winding turns of test cables are needed to know. Take the QFSN-300-2 generator for example, the core parameters are shown.

Inner diameter of the stator is $\mathrm{D} 1=1250 \mathrm{~mm}$.

Outer diameter of the stator is D2 $=2540 \mathrm{~mm}$.

Height of the core tooth is $\mathrm{H}=1635 \mathrm{~mm}$.

Length of the core is $\mathrm{L} 1=5200 \mathrm{~mm}$.

Numbers of the ventilating ducts is $n=63$.

Width of the ventilating ducts is $\mathrm{L} 2=8 \mathrm{~mm}$.

Core fill coefficient is $\mathrm{K}=0.93$.

According to state standard[2], the magnetic flux density in the test here is $\mathrm{B}=1 \mathrm{~T}$.

Effective sectional area of the stator is[3,4]:

$$
A_{J}=L * H=K *(L 1-n * L 2) * H=21029 \mathrm{~cm}^{2}
$$

Turns of the exciting cables is :

$$
W 1=\frac{U * 10^{8}}{4.44 f * A_{j} * B}=\frac{45 * U 1 * 10^{4}}{A_{j} * B}=12.8
$$

To achieve flux density high enough, we chooses 12 turns.

For other types of generators, we collect statistics of core parameters of domestic typical large turbo generators and get the winding turns needed in core loss test as shown in Table 1. 
Table 1 Diagram of corresponding relation between core perimeter and test turns

\begin{tabular}{|c|c|c|c|c|}
\hline $\begin{array}{c}\text { Generator parameters } \\
\text { capacity[MW] }\end{array}$ & $\begin{array}{c}\text { Core } \\
\text { perimeter[m] }\end{array}$ & $\begin{array}{c}\text { Length of a } \\
\text { signel turn [m] }\end{array}$ & Test turns & $\begin{array}{c}\text { Total length of all } \\
\text { turns [m] }\end{array}$ \\
\hline 160 & 15.1 & 17.1 & 16 & 273.6 \\
\hline 165 & 17.7 & 19.7 & 16 & 315.2 \\
\hline 300 & 20.4 & 22.4 & 12 & 268.8 \\
\hline 600 & 24.5 & 26.4 & 8 & 211.2 \\
\hline 1000 & 27.3 & 29.3 & 6 & 175.8 \\
\hline
\end{tabular}

To satisfy the need of all types of typical generator, the group of test cables are decided:

Six cables of $29.3 \mathrm{~m}$ length, two cables of $26.4 \mathrm{~m}$ length, four calbes of $22.4 \mathrm{~m}$ length, four cables of $19.7 \mathrm{~m}$ length.Thus, the total length of group of test cables is :

$$
L=(29.3 * 6+26.4 * 2+22.4 * 4+19.7 * 4) m=397 m
$$

Combination of test cables for typical generators' core loss test is shown in table 2, which is referred to when taking the core loss test.

Table 2 Combination of test cables for typical generator core loss test

\begin{tabular}{|c|c|c|c|c||}
\hline Length [m] & 19.7 & 22.4 & 26.4 & 29.3 \\
\hline 160 & & & & \\
\hline 165 & 4 & 4 & 2 & 6 \\
\hline 300 & $/$ & 4 & 2 & 6 \\
\hline 600 & $/$ & $/$ & 2 & 6 \\
\hline 1000 & $/$ & $/$ & $/$ & 6 \\
\hline
\end{tabular}

Swith cabinet. Switch cabinet is metal-enclosed, comprised of breaker, fuse, potential transformer, current transformer, low power factor watt meter, amperemeter, voltmeter, control and protection unit as shown in Fig. 1. 


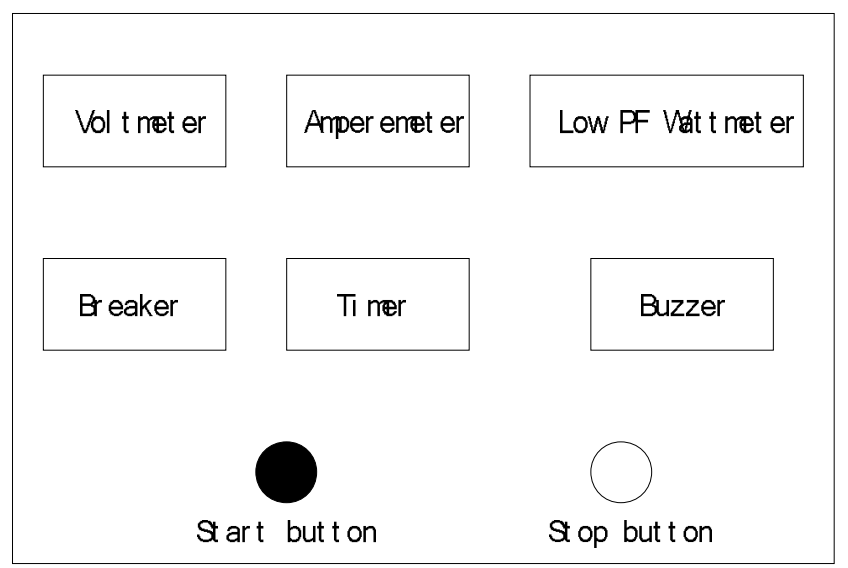

Fig. 1 Front view of switch cabinet

The switch cabinet is placed beside the generator for connection between test cables when operating the core loss test as shown in Fig. 2., where 1\# terminal and 32\# terminal are connected to 6kV assuming winding 16 turns, and 2\# terminal to 32\# terminal are connected to the group of test cables. Through nearby connection, the operation efficiency is largly improved while making the test safe and qualified while convenience is also achieved by incoporating meters without joining up kinds of meters again in separate.

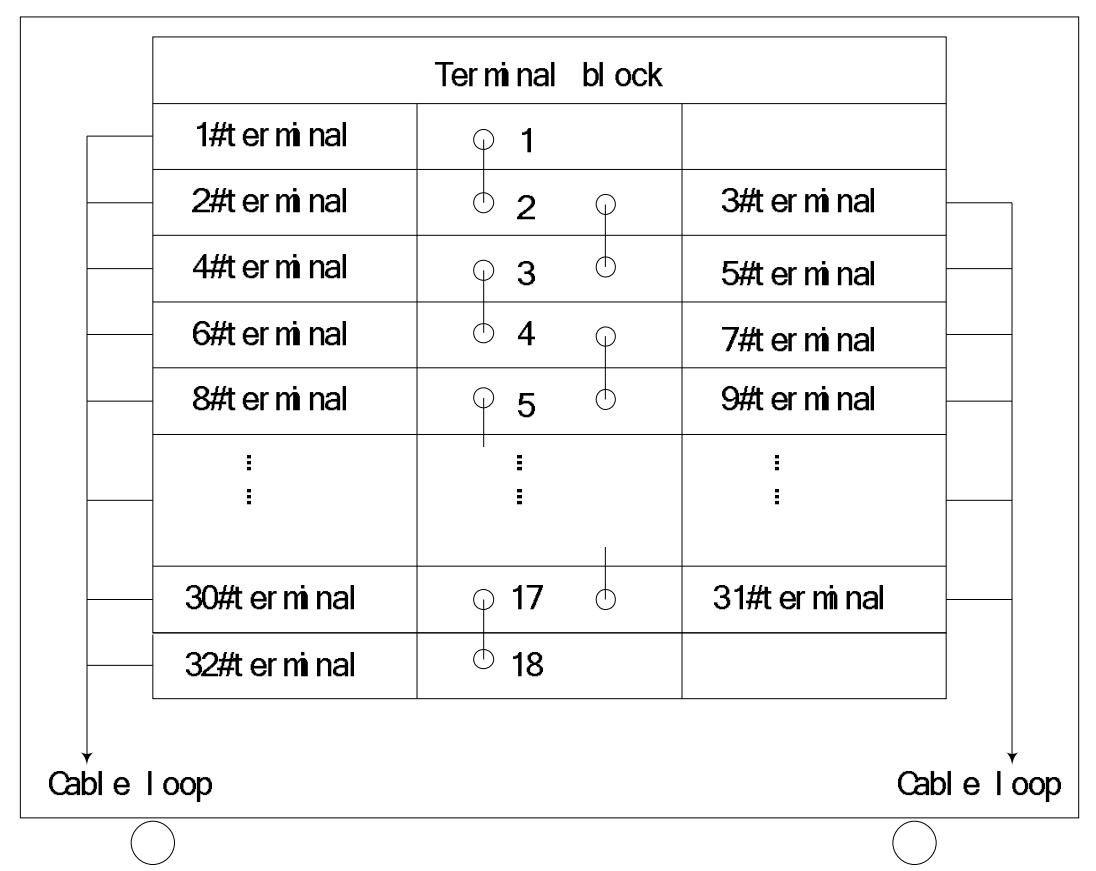

Fig. 2 Back view of switch cabinet

\section{Conclusion}

Through the use of a group of test cables substitute for a whole long test cable, combining with a switch cabinet especially designed here for connection, the generator core loss test could be easily conducted with high realiability not only in the cable connection section but also save great efforts when disconnect cables, meanwhile, time in the stator can be saved for technicians.

\section{References}

[1] Weiqing Li, Inspectional Analysis and Prenvention of Turbo Generator Damage, second ed., China Electric Power Press, Beijing, 2010, pp. 79-83. (In Chinese)

[2] DL/T596-1996<Preventive test code for electric power equipment> (In Chinese).

[3] L. Fan, H. Zhao, X. Li, Q. Li, D. Zhao, J. Hebei Electric Power. 12 (2012) 18-19 (In Chinese). 
[4] F. Sun, M. Li, J. Large Electric Machine and Hydraulic Turbine. 7 (2015). $28-29$ (In Chinese). 